\title{
To hoard or to share?: Strategic management of knowledge and ICTS in complex economic systems
}

\author{
Agustí Canals \\ Universitat Oberta de Catalunya (Spain) \\ acanalsp@uoc.edu
}

Received August, 2018

Accepted July, 2021

\begin{abstract}
Purpose: The purpose of this paper is to achieve a better understanding of the effects of strategic decisions related to the management of knowledge taken by organizations in complex economic systems. These effects are seen in the long term performance of organizations in the system choosing different strategic paths. As knowledge-related processes make intensive use of ICTs, the influence of the degree of development of these technologies is taken into account.

Design/methodology: An agent-based simulation model, ImbySim, based in the I-Space conceptual framework, is used to represent the evolution of a group of knowledge-intensive organizations located in a given geographic space. Those organizations engage, among others, in processes of creation and transfer of knowledge assets. Organizations show different levels of performance, which may be related to their knowledge-related strategic choices. The main knowledge-related strategies available for the agents are, on one side, sharing or hoarding knowledge and, on the other side, structuring or destructuring knowledge.
\end{abstract}

Findings: 'The results of the simulation suggest that it is not adequate to adopt an 'always sharing' or 'always hoarding' strategy. The hoarding or sharing of knowledge assets need to be applied in a discriminating way depending on the specific asset or the situation of the organization. Also, different levels of development of ICTs favour different strategic choices concerning the adequate structuring of knowledge assets and the degree of knowledge sharing. In general terms, ICT development calls for more sharing and more structuring of knowledge.

Practical implications: The hypotheses developed from this research may be very useful, once empirically tested, for strategic planning. Policy makers in charge of complex economic systems and firms and institutions present in them may benefit from the insights obtained and define their strategic moves according to them.

Originality/value: From the simulations, a number of empirically testable hypotheses have been extracted. Should these hypotheses get empirically corroborated, they would challenge a certain body of theorising-associated with organizational ecology and organizational demography-thus demonstrating the fruitfulness of the simulation approach to complex knowledge-based problems in the field of strategy.

Keywords: Knowledge management, Strategy, Information and Communication Technologies (ICT), Knowledge flows, Spatial location, Agent-based modeling 
Jel Codes: D83, L16, O33, C15

\section{To cite this article:}

Canals, A. (2021). To hoard or to share?: Strategic management of knowledge and ICTS in complex economic systems. Intangible Capital, 15(3), 148-172. https://doi.org/10.3926/ic.1358

\section{Introduction}

In a knowledge-based economy, the creation of new knowledge is viewed as a fundamental driver of economic development (Castells, 1996; Cohendet, Parmentier \& Simon, 2017; Leonard, 1995; Leonard \& Barton, 2014). Although continuous knowledge creation keeps organizations, regions and industrial clusters competitive (Asheim, Boschma \& Cooke, 2011; Boisot, 1998), without adequately thought out diffusion mechanisms - both within and across organizations - competitiveness will remain a haphazard business (Boisot, 1998; Klarl, 2014; Stein, Ridderstrale \& Sanchez, 2001; Winter, Szulanski, Choo \& Bontis, 2002). Knowledge created by a given agent at one point in time and space has to reach a second designated agent at another point in time and space, and has to do so accurately and in a relevant and timely fashion. Knowledge creation and diffusion, however, do not take place in a vacuum, but in a competitive environment in which imitation and appropriation can rapidly erode whatever competitive advantage such activities might confer on a firm (Almeida \& Kogut, 1999; Andreu, Baiget \& Canals, 2008). Furthermore, in an age of outsourcing, offshoring, and dense kaleidoscopic interorganizational networks, one in which information flows instantaneously, the clarity of the boundaries between internal and external organization often gets eroded, thus further limiting an agent's control over the diffusion of its knowledge. In a networked economy, therefore, the specific manner in which knowledge is first created by a given agent and then diffuses out to other agents-whether competitors or collaborators-becomes important (Appleyard, 1996; Ciborra \& Andreu, 2002; Klarl, 2014).

Economies are increasingly vulnerable to Schumpeter's "gales of creative destruction" in which the continuous creation of "new combinations" has become a survival imperative (McCraw, 2009; Schumpeter, 1983; Teece, 2000). It follows that the specific knowledge management strategies adopted by different types of organizations and institutions-economic, territorial, etc.-are likely to be important to their survival (Davenport \& Prusak, 1998; Hislop, Bosua \& Helms, 2018; Massingham, 2020; Oluikpe, 2012). The rapid development of the information and communication technologies (ICTs) is generally believed to have two distinct effects on the strategic options facing organizations attempting to manage their knowledge assets:

1. Where they lower data processing and transmission costs, ICTs facilitate and accelerate the process of knowledge creation and diffusion (Boisot, 1995a; Boisot \& Nordberg, 2011; Nee \& Swedberg, 2005).

2. Where they increase connectivity between unrelated agents, ICTs also act to further erode the boundary between internal and external organization (Barabási, 2002; DiMaggio, 2001).

The two effects can work in opposite directions. If the first enhances an organization's rent-generating capacities, the second makes it more difficult for the organization to initially appropriate and then hold on to rent so generated. Such a 'paradox of value' (Boisot, 1998; Boisot \& Nordberg, 2011) makes it both more difficult and more pressing for an organization to develop a strategic understanding of what knowledge management options it faces and how effective these might be. In this paper an agent-based simulation model written in the SWARM platform (Abar, Theodoropoulos, Lemarinier \& O'Hare, 2017; Minar, Burkhart, Langton \& Askenazi, 1996) is used to explore the strategic impact of ICTs on an organization's knowledge management options. The evolutionary approach adopted has one of two hypothesized outcomes:

- The organizational ecology outcome: The development of ICTs affects the selection environment in which organizations operate-i.e., their ecology - in ways that modify the organization's survival prospects, but over which managers have little or no influence (Hannan \& Freeman, 1989). 
- The strategic choice outcome: The development of such technologies affects the selection environment in which organizations operate in ways that maintains the relevance and influence of strategic choices made by managers (Child, 1972).

The approach used here is to first establish whether the differential distribution of knowledge management strategies-i.e., strategic choices-within a population of agents impacts the evolution and survival prospects of its members. Then, to look at how these survival prospects-and hence the value of strategic knowledge management choices - might be affected by different levels of ICT development. The simulation model implements a conceptual framework-the Information-Space or I-Space (Boisot, 1995a, 1998; Boisot \& Nordberg, 2011) — that explores how rapidly and extensively knowledge flows within and across a population of agents as a function of how far it has been structured. This approach builds on the assumption that the tacit knowledge possessed by our agents actually matters and that ICTs vary in their capacity to capture it. Agents in the model are taken as representing individual organizations belonging to a given industrial sector. Each agent is endowed with a fixed knowledge management strategy. The model is firstly run holding the level of ICTs development constant and then this level is varied. This work is exploratory. The model is used to generate fruitful hypotheses rather than to test them. The model will have proved its worth if others find the generated hypotheses—or some variant of these—worth testing empirically (Davis, Eisenhardt \& Bingham, 2007).

The structure of the paper is as follows. In the next section, 2, the main features of the I-Space are briefly outlined, identifying within the framework where strategic knowledge management choices are available to managers. After that, the main features of the agent-based simulation model that are relevant to our study are described. Then the results obtained from a number of model runs are presented. The paper concludes with a discussion of our results and a conclusion.

\section{A conceptual framework: The I-Space}

\subsection{The basic concepts}

Living things, considered as intelligent agents, survive by building up useful knowledge through a process of discrimination and association (Hahn, Chater, Lamberts \& Shanks, 1997) that structures information (Ancori, Bureth \& Cohendet, 2000; Machlup, 1983; Saviotti, 1998). Knowledge creation is the outcome of an active and constructive process in which an agent draws upon prior knowledge and experience to extract information from incoming stimuli that register with it as data (Boisot \& Canals, 2004). The I-Space posits that the extent to which information is structured affects both the speed and extent to which it can be shared within a population of agents. Information structuring-i.e., knowledge creation - is achieved by acts of codification and abstraction (Boisot, 1998; Boisot \& Nordberg, 2011). These two activities correspond to the biological processes of discrimination and association.

Codification, by clarifying the distinction between categories-both perceptual and conceptual-reduces the amount of data processing required to assign phenomena to them. When categories are well codified, phenomena can be assigned to them-i.e., coded-more rapidly and economically than when they are not.

Abstraction reduces the amount of data processing incurred by acts of categorization by reducing the number of categories that need to be drawn upon to adequately 'code' a phenomenon. By exploiting the correlational structures of knowledge(Saviotti, 1998, 2011) to allow one category to stand in for another, abstract representations draw on fewer categories than concrete ones.

The reductions in data processing achieved by codification and abstraction have the effect of speeding up communication processes. Messages can be formulated, encoded, transmitted, decoded, and interpreted with less noise, more rapidly and more reliably. Within a given time frame and a given communication budget, therefore, more agents can be reached with a message when it has been well structured than when it remains fuzzy and unstructured. Furthermore, the fuzziness and vagueness of unstructured messages typically can only be countered through feedback, redundancy and several channels working together, something that is typically achieved by face-to-face interaction and the co-presence of the communicating parties. With structured 
messages the transmission process can be more parsimonious, impersonal and single-channelled, allowing communication at a distance. The relationship between the codification, abstraction and diffusion of information is given in Figure 1.

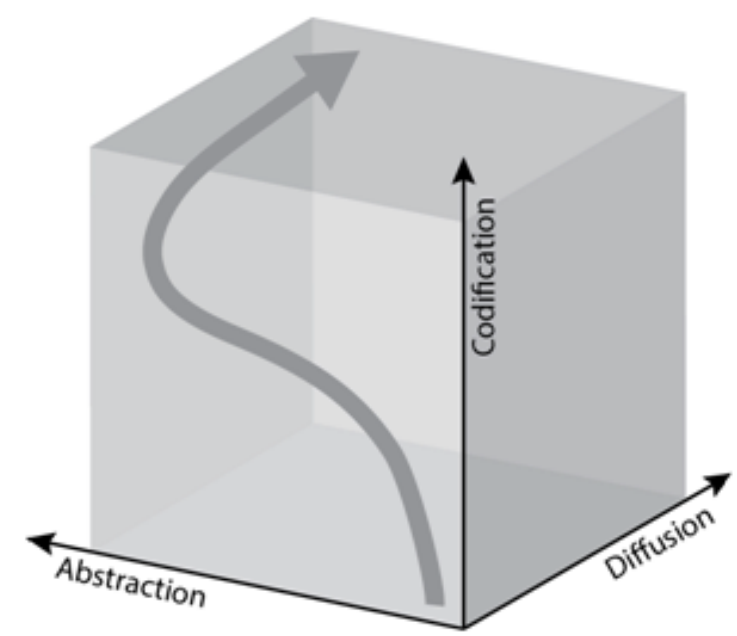

Figure 1. The diffusion curve in I-Space (Based on Canals, Boisot \& MacMillan, 2004; Boisot \&

Nordberg, 2011)

\subsection{The paradox of value}

Structuring information creates new knowledge without either invalidating or erasing the existing knowledge from which it arises (Boisot, 1995a). Intuitions and experiences that are initially vague and half-formed, over time get articulated, tested and stabilized. They can then be written down and transmitted to a larger population. They can also undergo another round of codification and abstraction, being further compressed into quantitative or mathematical codes, but the initial intuitions will typically survive in their original form. The process of formalizing knowledge in this way adds to its utility by making it both more robust and more transmissible. But increasing the transmissibility of knowledge in this way also potentially reduces its scarcity.

The economic value of any good is at its maximum when it is both useful and scarce. In the case of knowledge goods, however - and in contrast to that of purely physical goods-utility and scarcity are inversely related (Boisot, 1996). The increases in utility that are achieved by successive acts of codification and abstraction have the effect of rendering the scarcity of the knowledge good ever more precarious. Such knowledge becomes vulnerable to unintended spillovers. This 'paradox of value' is illustrated in Figure 2. Here it can be seen that the point of maximum value is located in a region of the I-Space in which the forces of diffusion are at a maximum. 


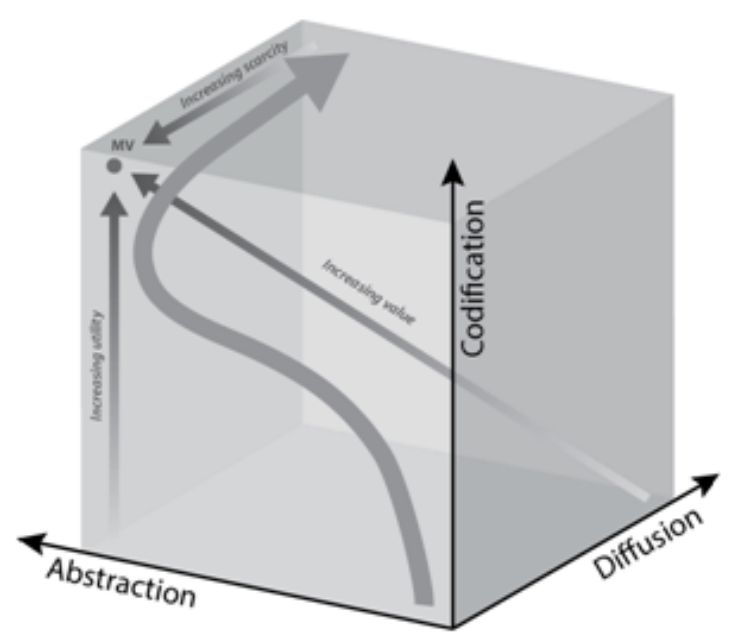

Figure 2. Maximum value (MV) in the I-Space (Based on Canals et al., 2004; Boisot \& Nordberg, 2011)

Organizations respond to the paradox of value in two ways. They can either attempt to tighten up their control of the diffusion process so as to reduce their unintended effects, or they can attempt to profit from the acceleration of the diffusion processes by voluntarily speeding up their own internal learning and innovation processes (Boisot, 1996). In the first case the costs incurred are those required to forestall spillovers-the costs of patents, copyright, secrecy clauses, etc.-in the second case the costs are those of creative destruction-i.e., of cannibalising existing products in order to make space for new ones.

\subsection{ICTs in the I-Space}

An important factor in the effective diffusion of information and knowledge is the level of development of ICTs. The appearance firstly of the telegraph, then of the telephone, and now more recently of computers, the Internet, and mobile telephony, has made it possible to gradually extend the reach of knowledge across space and time. Information that two hundred years ago could only be transmitted face-to-face through the movement of people can today travel the globe in a matter of seconds. Indeed, technological development constitutes a major factor in the emergence of an information society (Bell, 1999; Castells, 1996, 2001). The recent increase in bandwidth achieved by new ICT developments points to further improvements in the reach and speed of information transmission (Evans \& Wurster, 2000).

Any improvement in the capacity of data transmission implies—other factors remaining equal—a speeding up in the diffusion of information and knowledge, as well as an increase in the size of the population that can be reached in a given unit of time by a given message. Furthermore, as just pointed out, many ICTs developments also make possible increases in communication bandwidth. Bandwidth, however, turns out to be less important when transmitting structured knowledge than when transmitting unstructured knowledge. Thanks to improvements in ICTs, messages that had to be formally structured in order to be sent at all—such as through conventional mail—can now be sent in an informal and unstructured form using, say, e-mail or videoconferencing technology.

The introduction of more developed ICTs shifts the diffusion curve towards the right along the diffusion dimension in the I-Space as shown in Figure 3. As discussed, this shift has two quite distinct effects as indicated by the two arrows in the diagram. Firstly, there is a diffusion effect: for any given degree of codification and abstraction, a higher number of agents can now be reached with the same information per unit of time than hitherto-electronic mail, for example, allows us to reach a much higher number of people than a traditional letter, and faster. This is represented in the figure by the horizontal arrow. Secondly, there is a bandwidth effect: for any given number of agents that are targeted by a message, the bandwidth available for communicating with them increases. Contrary to what is commonly claimed in the literature, the relevant information can thus be 
transmitted at lower levels of codification and abstraction than hitherto-as, for example, when we substitute multimedia or videoconferencing for written communication. The downward-pointing arrow in Figure 3 depicts this second effect.

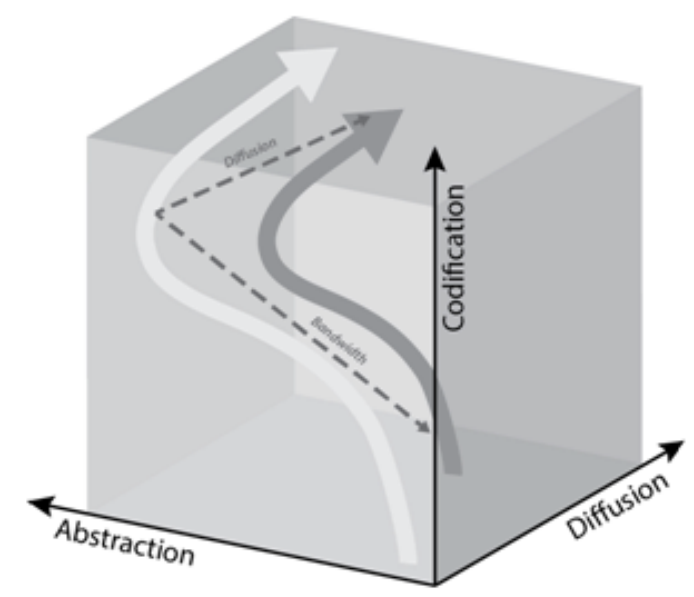

Figure 3. Information and Communication Technologies (ICTs) shift the diffusion curve in the I-Space. (Based on Canals et al., 2004;Boisot \& Nordberg, 2011)

\subsection{Knowledge management strategies}

The analysis of knowledge flows in the I-Space suggests that managers have two strategic levers that they can operate in pursuit of a given knowledge management strategy, a knowledge structuring lever and a knowledge hoarding lever (Boisot, 1995b):

- The Knowledge Structuring Lever - Managers can limit the natural diffusibility of the knowledge their organization creates and uses by controlling the extent to which they structure it. That is, they can decide how much to invest in the codification and abstracting activities that facilitate the diffusion of the knowledge they create. Note, however, that in doing so, they face a trade-off: by not structuring their knowledge, they refrain from increasing the utility of such knowledge to themselves and their collaborators in order to reduce its natural availability to others. Whatever knowledge they create will then enjoy a lower degree of reliability and standardization-and hence of robustness - than more structured knowledge would, so that it'sinternal use by the organization will also be less efficient.

- The Knowledge Hoarding Lever - Managers can invest in knowledge structuring-codification and abstraction—but then, by erecting barriers to its diffusion, attempt to limit the unintended spillovers that are likely to result say, through investments in intellectual property rights-patents, copyright, secrecy clauses, etc. With this second strategic lever, managers avoid the trade-offs of the first lever, but only by incurring a cost whose effectiveness will depend on the institutional strength of the property rights regime that they invest in.

The development of ICTs affects the costs and benefits of operating either lever. The diffusion effect will impact the performance of the knowledge-hoarding lever; the bandwidth effect will impact that of the knowledge-structuring lever. These impacts are hard to model analytically since much may depend both on the characteristics of ICTs evolution as well as on the nature of the strategic environment in which the choices are made. Knowledge structuring strategies, for example, may entail the loss of valuable tacit knowledge that underpins an organization's competitive advantages. And knowledge hoarding, in turn, may prove to be a suboptimal choice in a turbulent 'Schumpeterian' environment, where knowledge-sharing strategies often result in more profitable long-term outcomes (Boisot, Canals \& MacMillan, 2003). To gain insights into how ICTs modify 
the strategic knowledge management options of organizations, an agent-based simulation model will be used to explore the consequences of operating the two levers in different combinations. In the next section, ImbySim, the agent-based model used in this research and that implements the theoretical provisions of the I-Space is briefly described.

\section{ImbySim: An agent-based simulation model}

ImbySim is an agent-based simulation model that can represent a population of organizations, located in a geographical space, capable of creating and of sharing knowledge assets. ImbySim explores the knowledge management behavior of organizations as a function of their location in physical space. Since ICTs affect the spatial location of organizations, we will use the model to examine how the development of these technologies impacts their strategies.

In ImbySim, different agents, each representing an organization, hold a number of knowledge assets that are distributed throughout the I-Space and that each earn them different rents reflecting this distribution. Agents interact in a Schumpeterian regime characterized by the obsolescence of knowledge assets, their uncontrolled diffusion, and creative destruction. Agents can either create knowledge for themselves by investing their funds, or they can acquire knowledge assets from other agents through meeting and transacting with them. Agents earn rents from the knowledge assets they use and deploy some of the funds so earned either for the creation of new knowledge or for interacting with other agents. The performance of agents in the simulation depends both on their ability to generate funds and to make good use of them. An agent who fails to generate enough funds from its knowledge assets to assume the cost of investing in its strategies (i.e., creating knowledge or interacting with other agents), is 'cropped' (selected out) from the simulation.

ImbySim allows each member in a population of agents to represent an organization belonging to a given industrial sector and located within a given spatial region. The spatial location of organizations or the different establishments that make up organizations have an impact on the nature of knowledge flows and transfers both within and between organizations. Studies of the spatial economy show that the flow of knowledge between any two organizations depends, in part, on the spatial distance between them (Audretsch, 2000; Dunning, 2000; Storper, 2000). Two different—albeit strongly related—reasons can be invoked for this. First, spatial proximity facilitates face-to-face communication while spatial distance forces one to rely more on ICTs. Since in face-toface interactions the bandwidth at the disposal of the communicating parties is broader, it seems reasonable to suppose that the sharing of knowledge will generally be both faster, richer, and generally easier (Boisot \& Li, 2005). Second, spatial proximity usually implies a greater measure of shared context between communicating parties — cultural economical, social, linguistic, etc. (Hall, 1976). This also facilitates communication and, hence, a more effective sharing of knowledge. The ImbySim model has been previously verified and validated through its application to the modeling of high-tech geographical clusters. This application, together with a technical description of the model, are described in Canals, Boisot and MacMillan (2008).

In the simulations performed here, agents exercise the two knowledge management options that we presented above. The first option affects the level of knowledge structuring at which an organization wishes to operate. While organizations will always use a mix of both structured and unstructured knowledge, they can develop a strategic preference for one of these over the other. When this preference becomes a conscious strategic choice, it aims to have an effect on the rents that the organization obtains from its knowledge assets. A simplified version of this strategic choice is introduced in the simulation model. Some agents, which are called structurers, will show a propensity to increase the level of structuring of their knowledge assets (s) and some others, called de-structurers, will show the opposite tendency.

Thus, the Knowledge Structuring Strategy (KSS) is the predisposition of a given organization to increase (KSS = 1) or decrease $(K S S=0)$ the level of structuring $s$ of its knowledge assets. For instance, let us suppose that an $\mathrm{R} \& \mathrm{D}$ specialist in a chemical company has an idea for a new production process. That is a newly created knowledge asset for the firm. While that idea is still in his mind, it will have a low level of structuring. The value of its s will be low. Indeed, the process stays in a tacit, not codified, and concrete form in his head. At this point, 
the company may adopt different strategies with that knowledge asset. If the firm has a predisposition to keep that knowledge in this form, for example for fear of leakages to the competitors, we may say that it is adopting a de-structuring strategy $(K S S=0)$ and the value of the knowledge asset's s will remain low. Contrarily, if the firm follows a policy of having all its processes carefully described and documented in a knowledge database in order to be able to diffuse them within the company or even outside, and perhaps even to serve as a stepping stone to develop other knowledge assets, we may say that it shows a structuring strategy (KSS $=1)$.

The second knowledge management option that agents can operate on is labelled diffusion blocking. Organizations can choose to share or to hoard their knowledge assets. They can either allow their knowledge to flow freely and unhindered and hope that this will influence the sector and the marketplace in their favor-such as, for example, when they contribute to the creation of open standards - or they can attempt to block the unintended diffusion of knowledge once it has been codified and abstracted-by means, for instance, of patents, copyright or secrecy clauses. Again, the choice made by the organization will influence the rents it obtains from its knowledge assets and thus its ability to survive. In our model, these two possible Diffusion Blocking Strategies (DBS) will be represented respectively by hoarding and sharing agents. The former will tend to block diffusion (DBS $=1)$, while the latter will tend to foster diffusion (DBS $=0$ ).

Thus, one finds in the simulations four types of agents each with distinctive strategic options with respect to the diffusion and the structuring of their knowledge assets: 1) boarding structurers, 2) boarding de-structurers, 3) sharing structurers and 4) sharing de-structurers. The exercise of such strategic choices by agents (Child, 1972) introduces a limited amount of variety and hence of evolution into the simulation. While values of the variables representing different knowledge management strategies remain unchanged over the life of an agent, they are inherited by any agent created by mergers, joint ventures, or subsidiaries, through a recombination mechanism similar to that which underpins genetic algorithms (Holland, 1992; Mitchell, 1996). In the case of subsidiaries, the values of the single parent's "genes" are inherited in toto by the subsidiary agent. In the case of mergers and joint ventures, the principles of Mendelian genetics apply: the "genes" of either parent agent are assigned to the newly created agent on an equi-probable basis (Mayr, 1982). There is also some degree of inheritance in the location assigned to new agents that are created as subsidiaries of an existing parent agent or as fruit of mergers or joint ventures between existing agents. The former will have higher likelihood of locating in the vicinity of their parent agent and the latter show higher probability of locating near one of the two parent agents.

This model, then, exhibits evolutionary behavior at the population level. First, although the strategic preferences of each organizational agent are fixed, their relative frequency in the simulation's organizational population can vary with the evolution of the system over time. Second, in the case of joint ventures, mergers and subsidiaries, the new organizational agent's spatial proximity to one of the parents' grid location in space is inherited. The spatial location of the organizational population will thus evolve over time, and, given, the dependence of knowledge diffusion on spatial distance, will influence the evolution of the knowledge management strategies chosen by agents. What results is, effectively, a co-evolutionary model of knowledge management strategies and spatial locations in an organizational population.

Since the impact of spatial location is modified by the degree of development of ICTs, the co-evolutionary process will also be affected by how these technologies evolve. Therefore, a parameter $\beta$ is introduced into the model as a measure of the level of development of ICTs. This parameter is introduced, indeed, to account for the level of development of ICTs. In our model, a higher level of ICTs development means basically an increase in the capacity of data transmission. In the I-Space framework, as explained in section 2, increasing bandwidth results in the possibility of transmitting richer content (i.e., less structured knowledge) to a larger population.

Thus, in our simulation model higher values for $\beta$ simultaneously increase both diffusion effects and bandwidth effects, thus facilitating the diffusion of knowledge-whatever its level of codification and abstraction-between agents at different grid locations. As ICTs evolve to increase the available bandwidth, however, the effective difference between communication strategies requiring the spatial contiguity of the parties and those requiring technological support begins to attenuate. In sum, the higher the value of $\beta$ in the model, the higher the level of 
development of ICTs, and hence the lower the impediments to effective and efficient communication attributable to spatial distance, $r$.

Since in this research the focus is on how ICTs development impacts the knowledge management strategies of agents, two things need to be ascertained: 1) does having a knowledge management strategy actually matter? 2) is the effectiveness of such a strategy affected by the development of ICTs? Clearly, if having a knowledge management strategy matters, then some agent strategies will be more effective than others, and organizations or institutions adopting such strategies will survive longer and give rise to a larger number of new agents-the products of mergers, joint ventures and subsidiaries - that subsequently inherit the strategies. In the long run, perhaps only some strategies will survive, with others being driven to extinction. Could the surviving mix of strategies then be altered by the evolution of ICTs? The fact that the outcome to such a question cannot be predicted ex ante on analytical grounds alone points to the potential of simulation modeling in addressing complex issues. Although such modeling does not directly deliver usable predictions, it can yield original insights and empirically testable hypotheses(Carley, 1999; Davis et al., 2007).

\section{Model runs and results}

Firstly, a comparison is made between the simple cases in which the two knowledge management strategies, KSS (Knowledge Structuring Strategy) and DBS (Diffusion Blocking Strategy), are taken as identical for all agents, with the case in which they are randomly distributed across the agent population. As there are four possible strategic combinations (Table 1), there are four simple cases, one for each strategy (Hoarding Structurers, Hoarding De-structurers, Sharing Structurers, Sharing De-structurers) and one mixed case in which at the beginning those four strategic options will be randomly assigned to the initial agents, resulting in approximately $25 \%$ of the agents pursuing each one. In the latter case, those new agents created by existing agents will inherit their strategic options from their parent agents. In all cases we select the same value for $\beta(\beta=2)$. Secondly, the simulation is run allowing the value for $\beta$ to vary in order to explore the impact of different ICT regimes on the performance of the two knowledge management strategies, namely, KSS and DBS.

\begin{tabular}{|c|c|c|c|}
\hline \multirow{2}{*}{\multicolumn{2}{|c|}{ STRATEGIC OPTIONS }} & \multirow{2}{*}{\multicolumn{2}{|c|}{$\begin{array}{l}\text { Knowledge Structuring Strategy } \\
\text { (KSS) }\end{array}$}} \\
\hline & & & \\
\hline & & $K S S=1$ & $K S S=0$ \\
\hline \multirow{2}{*}{$\begin{array}{l}\text { Diffusion Blocking Strategy } \\
\text { (DBS) }\end{array}$} & $\begin{array}{c}\text { Hoarding } \\
D B S=1\end{array}$ & Hoarding Structurers & $\begin{array}{c}\text { Hoarding } \\
\text { De-structurers }\end{array}$ \\
\hline & $\begin{array}{l}\text { Sharing } \\
D B S=0\end{array}$ & Sharing Structurers & $\begin{array}{c}\text { Sharing } \\
\text { De-structurers }\end{array}$ \\
\hline
\end{tabular}

Table 1. Strategic knowledge management strategies available for agents in ImbySim

To obtain statistically meaningful results, each case is subjected to 50 runs and average values of the significant measures are used to perform the analysis. Each run has a duration of 500 periods. This is a sufficient number of periods to ensure that the system reaches a stable state. The qualitative patterns that are described here appear to be robust across a wide range of parameter settings.

\subsection{Single versus mixed strategies}

Do the different knowledge management strategies each yield distinctive outcomes when all agents pursue the same one? And what kind of outcome do we get when agents each get assigned different strategies? To answer these two questions, the simulation is run for the five cases described above. First, looking at the four cases in which agents all pursue identical strategies and, therefore, there is no heritable variation. Then compare these four cases are compared with the one in which variation in strategy across agents is allowed. Here the four different strategies are randomly assigned to agents and newly created agents either inherit one of their parents' strategies, or as new entrants, they are randomly assigned a strategy. In all cases, other settings remain the same. 


\subsubsection{General evolution}

Figure 4 shows the effects throughout all 500 periods of the four different single knowledge management strategies as well as those of the mixed strategies. For each treatment Figure 4 gives the number of agents in the simulation, the number of knowledge assets, and the rents generated. In each chart, the dashed curves represent the evolution of the mean values of the relevant variables for 50 runs of each strategy. The solid curve corresponds to the mixed strategy case.
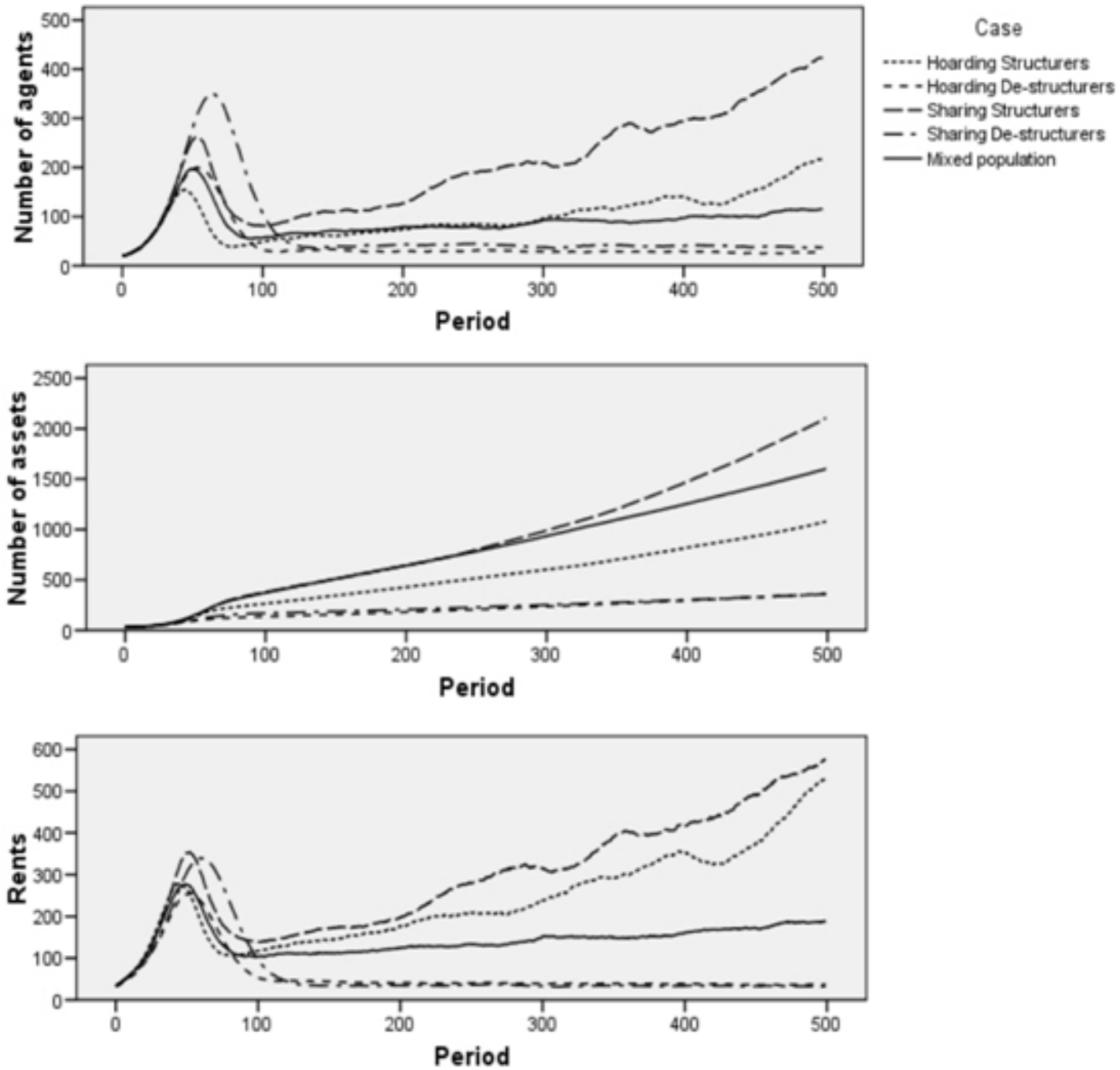

Figure 4. Comparison of the evolution in the number of agents, number of knowledge assets and rents obtained from knowledge assets for the four single strategy cases and the mixed strategies case. Average values for 50 runs in each case

The marked increase and subsequent decrease both in the number of agents and in the total amount of rents these earn applies to all five cases and suggests that the two variables are correlated. To some extent they must be since without rental income, an agent does not survive. Such behavior-an initial increase and a subsequent decrease followed by a stabilization — has been observed in other simulation models of this type (Barron, 2001). In other models using empirical real data (Carroll \& Hannan, 2000; Hannan \& Freeman, 1989; Levinthal, 1997) this kind of behavior is attributed to the emergence of order after an explosive phase in the first periods. However, in the two cases where there is a general preference for structuring knowledge assets, agents continually increase in number after the rise and fall of the early chaotic periods as compared to those without this preference. As can be seen from Figure 4, the mixed strategy case - the solid line-occupies an intermediate position, 
suggesting a possible relationship between the structuring of knowledge assets and the carrying capacity of the system. However, in this simulation, since knowledge can be applied across markets, the rents that agents earn from their knowledge are not constrained by the size of any given market, and so—in a manner reminiscent of the computer industry in the 1980s or the software industry in the 1990s-the number of knowledge assets shows positive growth in all periods.

To summarize thus far:

1. When they are unique, different knowledge management strategies deliver different levels of performancei.e., the model effectively discriminates between strategies.

2. In a world of mixed strategies, on average, they deliver an intermediate level of performance.

\subsubsection{General analysis of the final periods}

Figure 5 depicts the creation of knowledge assets and the rents generated by agents over the last 100 periods of the simulation. While more than one agent can possess the same knowledge asset, here it counts as just one asset.

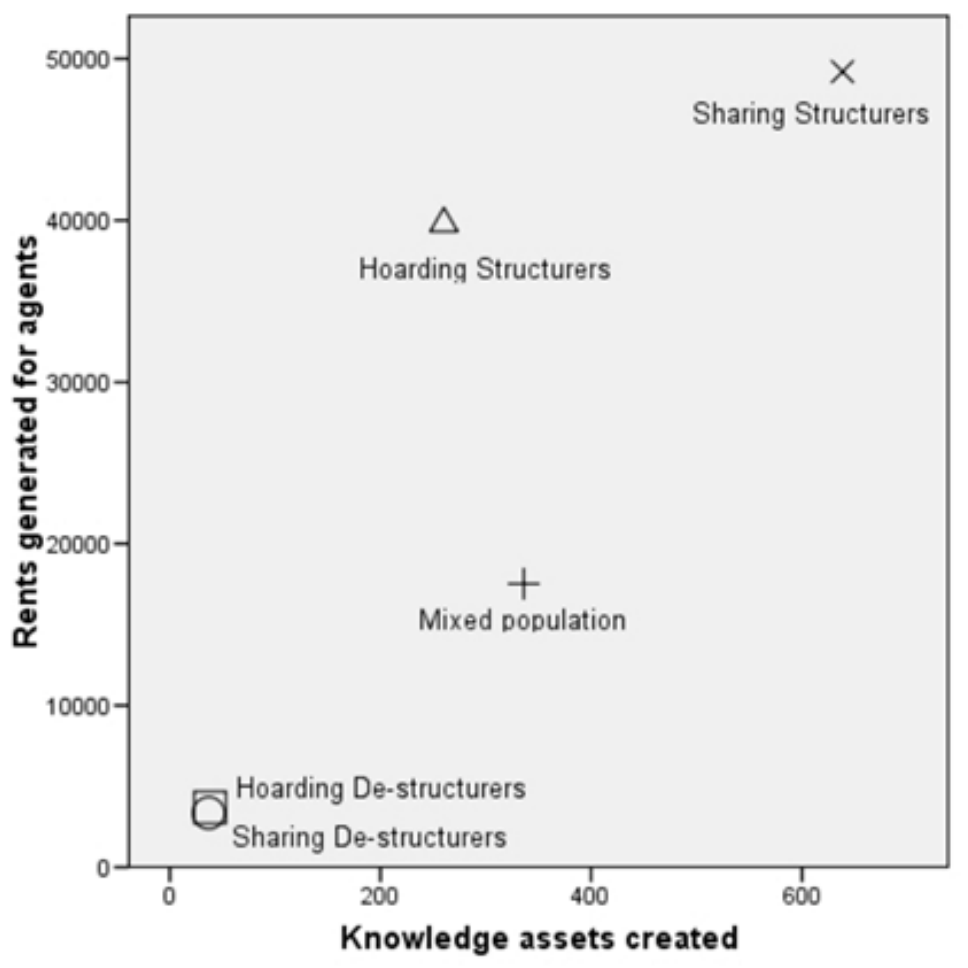

Figure 5. Number of knowledge assets created by agents compared to the rents acquired by the same agents for the five cases analyzed. Average values for 50 runs performed

From the figures we note three things:

- Structuring knowledge without blocking its diffusion generates the largest number of new knowledge assets as well as the highest rent level captured by agents. Here, the amount of knowledge created reaches a maximum, but society pays agents more for the knowledge generated.

- Structuring knowledge while blocking its diffusion yields the second highest rents per knowledge asset for agents but generates only the third largest number of knowledge assets. 
- The mixed strategy case yields the second highest level of knowledge asset creation but achieves a comparatively low rent per knowledge asset for agents. Here, society pays less but gets more knowledge assets.

Figure 6 shows the average residential time in the simulation of agents that are present and active within the last 100 periods of the runs against the rents obtained by these agents during their residency (the expression "residential time" is used here because agents can leave the simulation through two different processes: being "cropped" due to bankruptcy or deciding to exit after a sustained successful performance). Clearly, when all agents refrain from structuring their knowledge, they achieve a longer residential time than in the case where they all structure their knowledge, since in the first case spillovers are minimal. What is striking, though, is that the mixed strategies case achieves the lowest residential times of all while achieving the second highest level of rent generation.

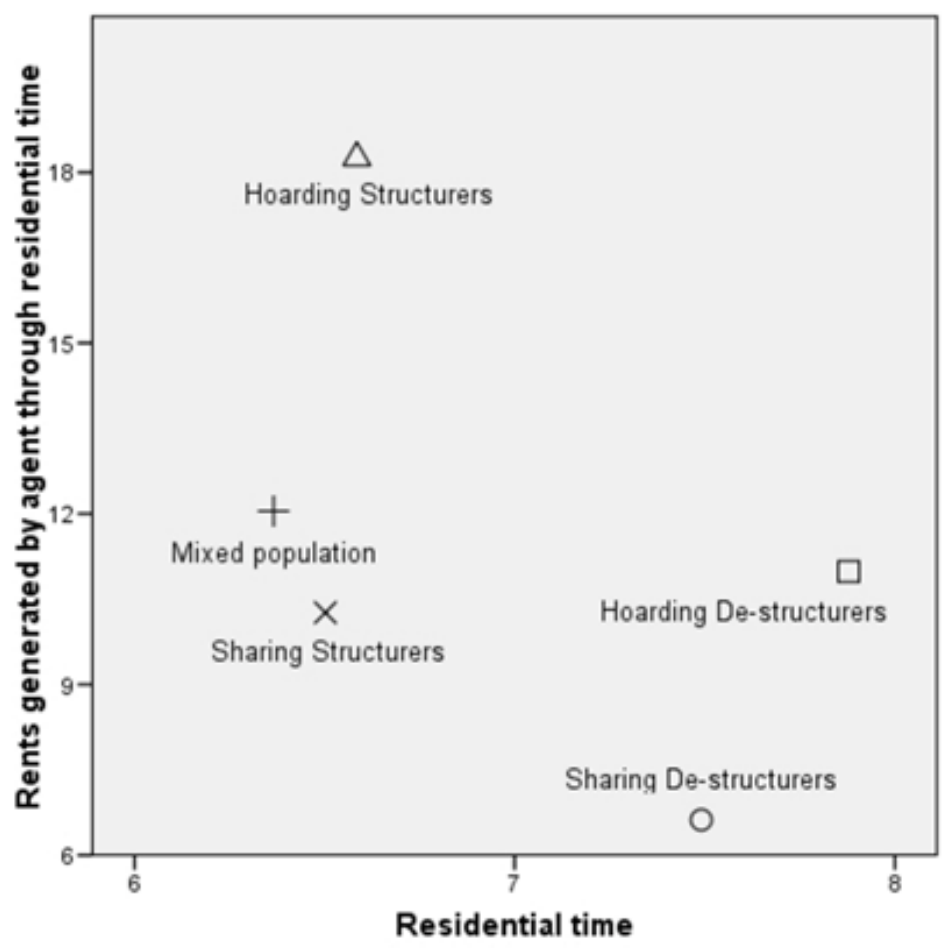

Figure 6. Rents generated by agents with residence in the simulation during the last 100 periods compared to residential time in periods. Average values for 50 runs performed

Again, we note two things:

- Where agents refrain from structuring their knowledge, they enjoy the longest residential time. But unless they also block diffusion, their stay is relatively profitless.

- On the other hand, where agents tend to both structure their knowledge and block its diffusion, they experience short residential times, but during their brief stay they earn the most rent.

Having shown that the simulation model turns in a distinctive performance where each strategy is pursued by all agents, we now briefly focus on the case of mixed strategies. Figure 7 depicts changes over time in an agent population pursuing a mix of all four strategic options. Over the long run, knowledge-sharing strategies clearly come to dominate. The simulation evolves from an initial 50/50 mix of strategies with respect to structuring to a situation in which sharing de-structurers progressively outnumber sharing structurers. By contrast, the diffusionblocking strategies quickly get "selected out" remaining present at a low level until the end of the simulation. 
From an initial approximate 50/50 mix of strategies with respect to knowledge-blocking also randomly assigned to agents they rapidly fall to below $5 \%$ from period 100 onward. In competition with the non-diffusion-blocking strategies, the hoarding strategies appear to deliver lower survival prospects.

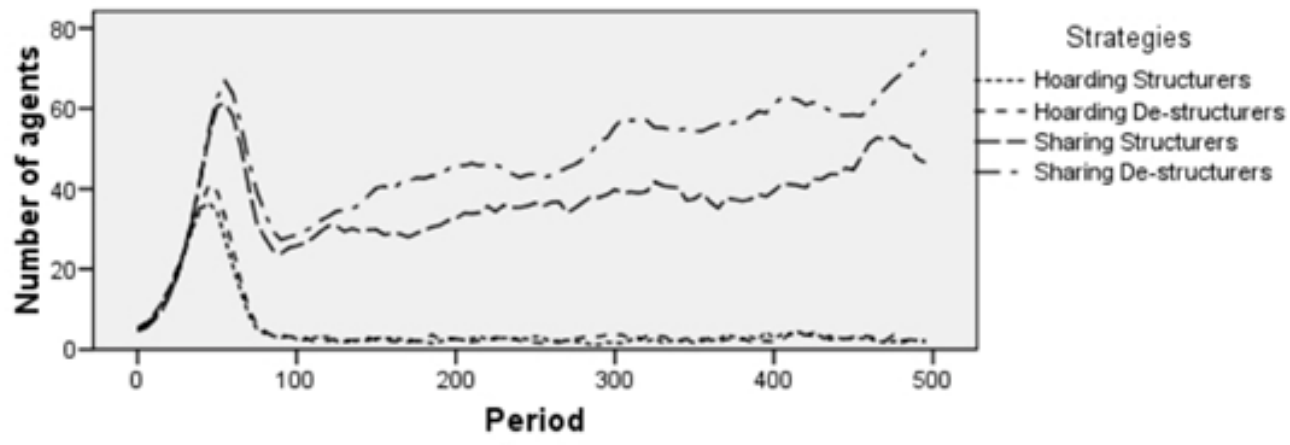

Figure 7. Evolution of the mix of coexisting KM strategies in the population.

Average values for 50 runs

\subsection{ICT regimes}

In this section, the behavior of agents under different ICT regimes as indexed by the parameter $\square$ is examined. Recall that high values of $\beta$ correspond to high levels of ICT development.

For different values of $\beta$, Figure 8 shows the mean number of agents in the simulation in the last 100 periods, the mean residential time of those agents and the rents that those agents generate per period. The results seem to point to non-linear behavior for all three values in their dependence from $\beta$. This is confirmed when we represent the same values in Figure 9 using a logarithmic scale for the horizontal axis, which represents the values of $\beta$. A logarithmic scale is used because in ImbySim, the dependence of the probability of interaction on $\beta$ takes an exponential form(see Canals et al., 2008).

Although the number of agents in the simulation decreases with $\beta$, a clear inflexion point can be inferred around $\beta=10$. Moreover, the mean residential time of agents and the mean rents those agents get per period show nonlinear behavior between $\beta=1$ and $\beta=5$ reaches a maximum between those values. It may be seen that after $\beta=1$ there is an increase in residential time and a slight decrease in rents earned until both graphs resume their initial trend. 

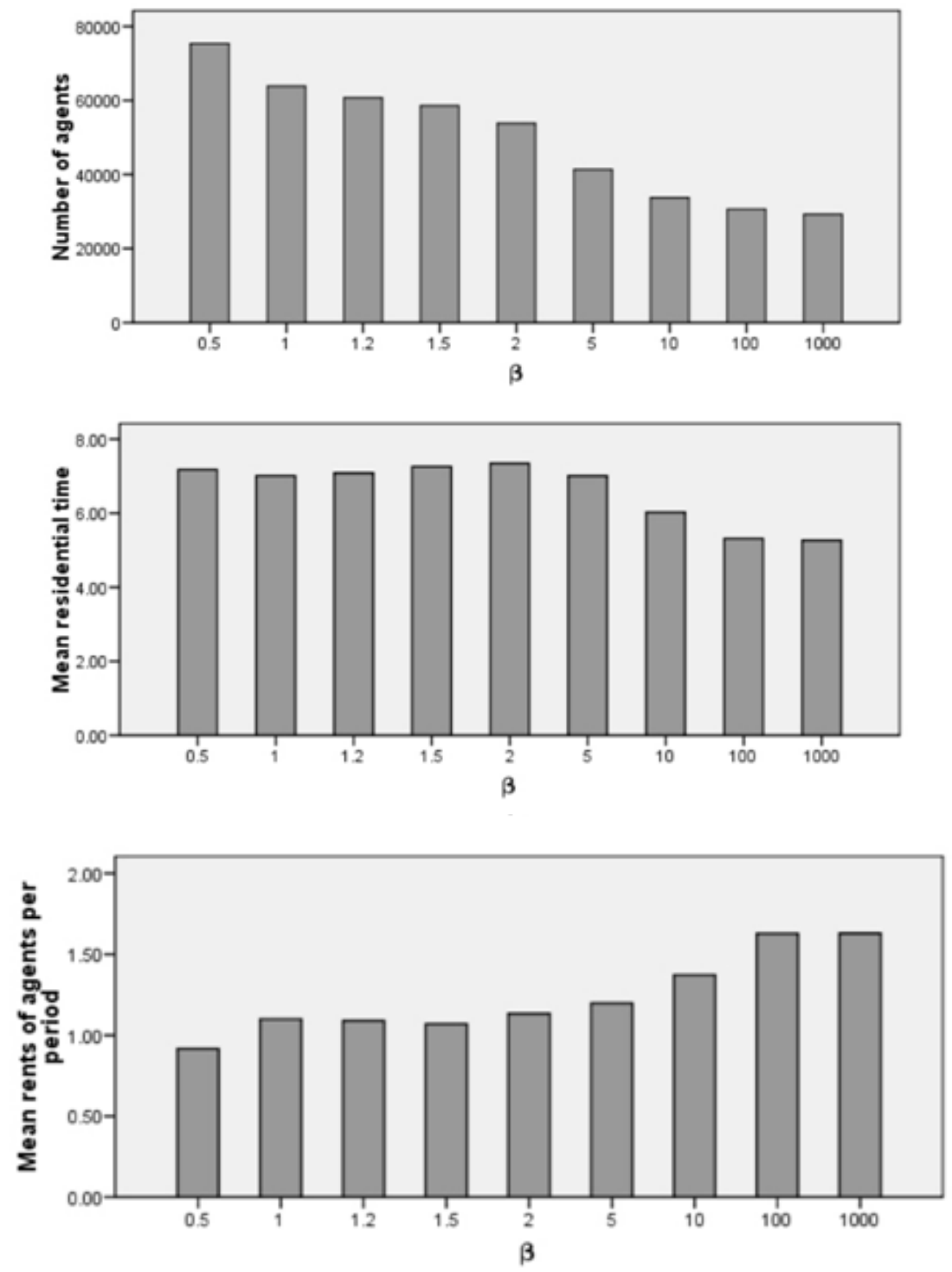

Figure 8. General analysis of the 100 last periods of the simulation for different values of $\beta$ : number of agents present, mean residency time of agents and mean rents obtained of those agents per period. Average values for 50 runs 

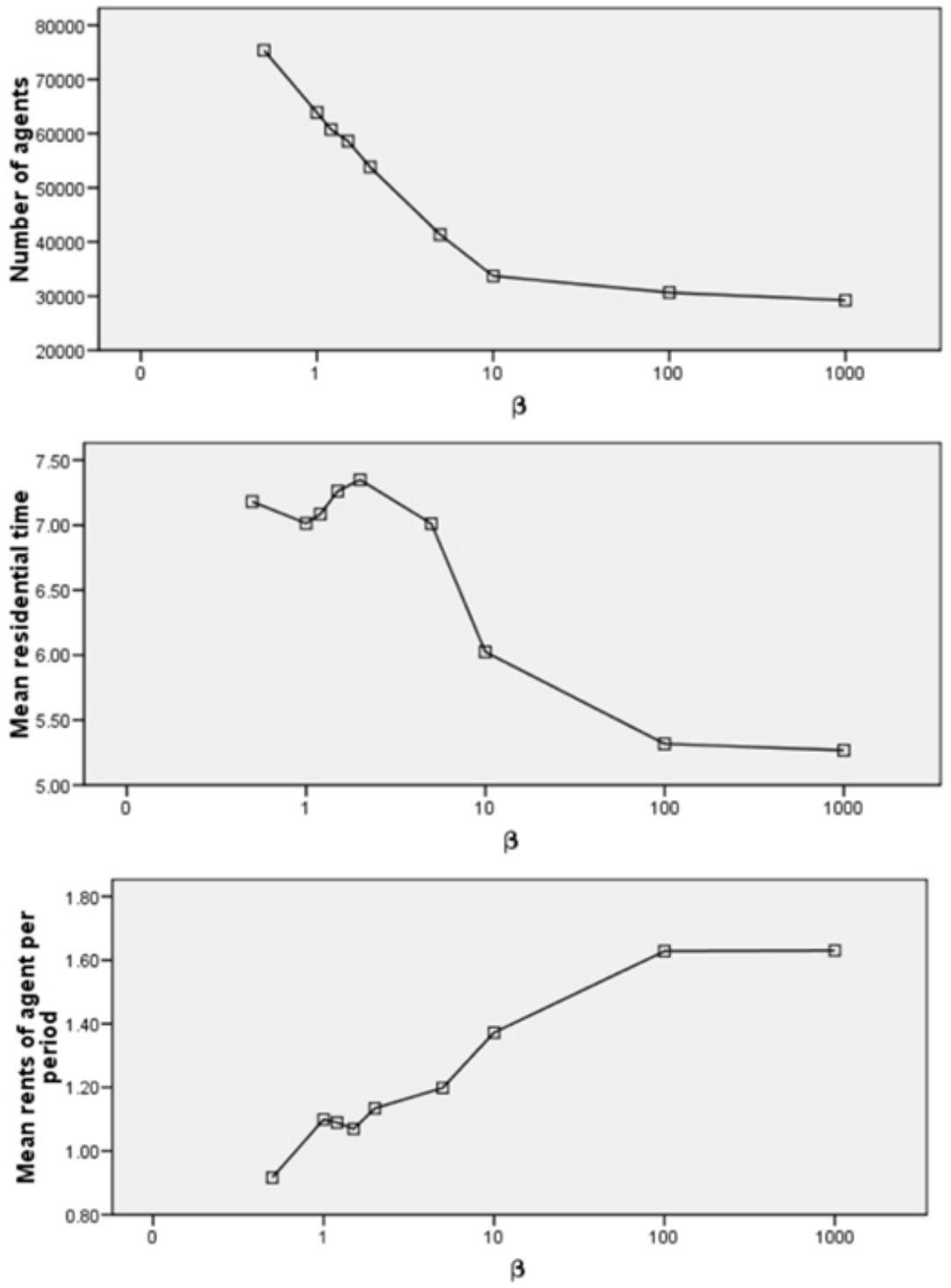

Figure 9. General analysis of the 100 last periods of the simulation for different values of $\beta$ using a logarithmic scale. Average values for 50 runs

Non-linear behavior associated with changes in ICTs is also evident when looking at the mix of strategies, especially with respect to the two sharing strategies. Figure 10 shows that the number of sharing structurers reaches a maximum at $\beta=1$ while at the same time the number of sharing de-structurers shows a local minimum.

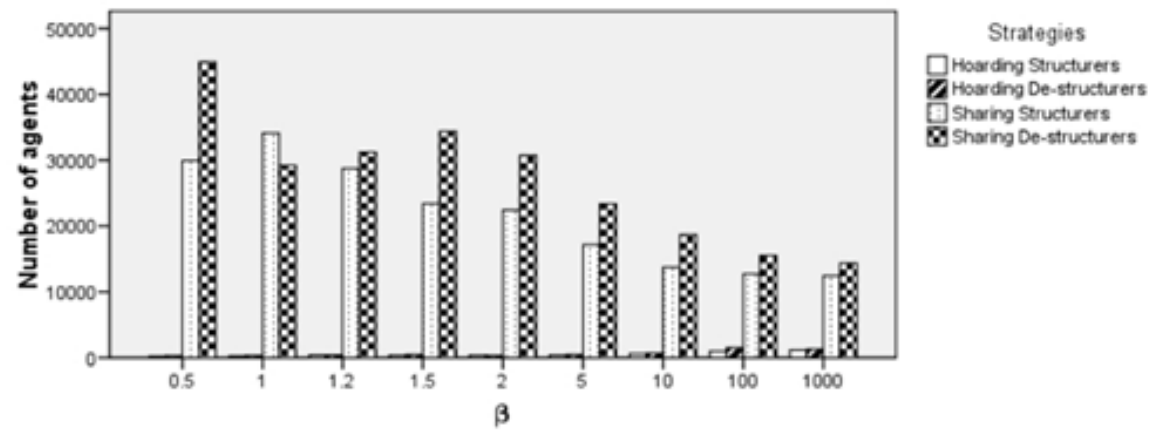

Figure 10. Strategic mix in the 100 last periods of the simulation for different values of $\beta$ 
Figure 10 suggests that the non-linearities are strongly related to the mix of strategies being pursued by agents as well as to the mean residential time in the simulation of agents pursuing different strategies. This is confirmed by Figure 11, which shows that the variation in mean residency time differs across the four strategies. This points to the internal characteristics of the populations of agents as possible causes of these non-linear effects. This issue is further explored in our discussion.

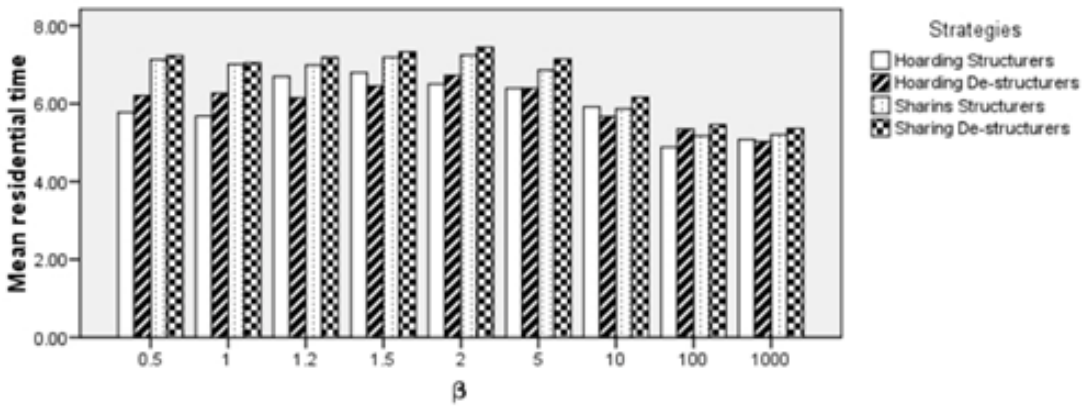

Figure 11. Mean residency time of agents pursuing different strategies in the 100 last periods of the simulation for different values of $\beta$

\section{Discussion}

Having established that the simulation can distinguish between the different knowledge management strategies of agents and delivers a different performance for each of these, what insights may be gained from the simulation runs? One striking feature is the way that the distribution of knowledge-structuring and diffusionblocking strategies across agents evolves as the simulation progresses. As Figure 7 dramatically demonstrates, diffusion-blocking clearly only works for a minority of agents. This suggests the following hypothesis:

Hypothesis 1: Given the increasing costs of protecting intellectual property rights as ICTs evolve, only organizations that apply such rights in a discriminating way to specific knowledge assets in specific industries are likely to be successful.

This is effectively a presumption in favor of sharing rather than of hoarding knowledge assets. But both the sharing and the hoarding of knowledge assets need to be applied in a discriminating way. The critical skill will be to identify which assets should be hoarded, and then to establish how far to hoard them for best performance. An organization thus needs an asset-specific knowledge management strategy rather than an organizationspecific one. And as Figure 10 indicates, while the evolution of ICTs imposes a greater requirement for some hoarding by organizations, the overall presumption is still in favor of sharing. These results lend some support to the plea made by Lawrence Lessig in favour of looser property rights (Lessig, 2002) - the results obtained suggest that these will benefit organizations as much as they will society (Boisot, MacMillan \& Han, 2007).

The mean residency times of agents in the simulation reflects the knowledge structuring and diffusion blocking strategies that they adopt. Concretely, agents adopting a hoarding strategy show lower residency times than those adopting a sharing strategy (Figure 11).

But to understand the causes that underpin the relationship between the two strategies requires a deeper analysis. For that, we look at the mean residency times of the four different types of agents that we have in that phase of the simulation-new agents created from scratch, from joint ventures, from mergers and from the creation of subsidiaries - which exhibit the strongest evolutionary behavior: during the first 100 periods rather than the last 100 periods (Table 2). 


\begin{tabular}{|c|c|c|c|}
\hline \multirow{2}{*}{$\begin{array}{c}\text { Diffusion } \\
\text { Blocking } \\
\text { Strategy } \\
\text { (DBS) }\end{array}$} & \multirow[b]{2}{*}{ Agent type } & \multicolumn{2}{|c|}{ Variables } \\
\hline & & $\begin{array}{c}\text { Number of } \\
\text { agents }\end{array}$ & $\begin{array}{c}\text { Mean } \\
\text { residency } \\
\text { time }\end{array}$ \\
\hline \multirow{8}{*}{$\begin{array}{l}\text { Sharing } \\
D B S=0\end{array}$} & \multirow{2}{*}{ Joint Venture } & 221 & 6.57 \\
\hline & & (124) & $(0.75)$ \\
\hline & \multirow{2}{*}{ Merger } & 71 & 11.74 \\
\hline & & (41) & $(1.20)$ \\
\hline & \multirow{2}{*}{ Normal } & 5 & 18.20 \\
\hline & & (2) & (7.56) \\
\hline & \multirow{2}{*}{ Subsidiary } & 65 & 9.55 \\
\hline & & (28) & $(1.23)$ \\
\hline \multirow{8}{*}{$\begin{array}{c}\text { Hoarding } \\
D B S=1\end{array}$} & \multirow{2}{*}{ Joint Venture } & 117 & 7.01 \\
\hline & & (80) & $(0.93)$ \\
\hline & \multirow{2}{*}{ Merger } & 40 & 10.91 \\
\hline & & (27) & (1.49) \\
\hline & \multirow{2}{*}{ Normal } & 6 & 20.94 \\
\hline & & (2) & $(7.67)$ \\
\hline & \multirow{2}{*}{ Subsidiary } & 22 & 9.79 \\
\hline & & (13) & $(2.13)$ \\
\hline
\end{tabular}

Table 2. Mean values (with standard deviation in brackets) of the number of agents and their mean residency time for each type of agent strategic option in the first 100 periods of the simulation

Surprisingly, for three of the four types of agent, the mean residency time in the first 100 periods of the simulation turns out to be longer if they adopt a hoarding strategy than if they do not-in contrast to what it is found when looking, ignoring their type, at the mean residency time of the agent group with a blocking strategy towards the end of the simulation (Figure 11). Only mergers yield a shorter residency time for agents in the simulation if they choose to block diffusion. And although agents created through mergers come only second in terms of frequency (Table 2), their impact would seem to be strong enough to lead to the reduction in mean residency time of the hoarding agents group as a whole as the simulation advances to the last periods. Is that possible? Is there any distinctive characteristic of mergers that could have this effect?

A careful analysis of the dynamics of the simulation could give us some hints. In a merger formed by two parent agents, the new agent receives all of its knowledge assets from both parents but inherits its KM strategy from only one of the parent agents. The mergers that happen to perform badly, and therefore reduce the mean residency time of created agents, are those that proceed from parent agents each originally having different DBSs, but which then both adopt a hoarding strategy (DBS =1) after the merging process. The costs to merged organizations of indiscriminately blocking diffusion for all of their inherited knowledge assets when one of the parents accumulated its share of such assets free of this cost can fatally overburden the new agent. Thus, while for the other types of hoarding agents there is no mechanism that significantly lowers their mean residency times relative to that of their counterparts with sharing strategies, for merger agents the mechanism described above is responsible for drastically reducing their mean residency time. It could be possible that this distinctive feature of mergers is passed on by inheritance to other types of agents through the mechanisms of constituting joint ventures and subsidiaries as the simulation evolves. Those new agents would have also shorter residency times and a hoarding strategy, what could end up slightly impacting negatively the mean residency time of the hoarding agents group as a whole towards the end of the simulation.

In any case, based on the observation of mergers in the simulation, we may propose the following:

Hypothesis 2: Two companies that merge, each having different hoarding propensities, will incur higher property rights protection costs relative to the average value of their merged knowledge assets if the merged entity indiscriminately applies the more stringent of the two pre-merger entities' hoarding strategies.

This hypothesis provides a second and independent argument for an asset-specific rather than an organizationspecific knowledge management strategy. 
Hypothesis 3: There is a negative correlation between the mean life expectancy of organizations using a knowledge structuring strategy and the amount of rents earned by these organizations. In fact, there is a trade-off between life expectancy and rent maximization that benefits the organization population as a whole, but not specific organizations.

Of course, this is exactly what patent protection is meant to achieve: society offers organizations a limited period of time during which an organization can earn monopoly rent in return for codifying its knowledge. In our model, the 'life expectancy' of an organization refers to the time during which it can stay in the simulation and earn monopoly rents. We see this phenomenon at work today in the pharmaceutical industry where many drugs are currently coming off-patent and many organizations are trying to prolong patent life in response to prospective declines in revenues (see "Prescription for change", The Economist, Jun 18th 2005, Special section: "A survey of pharmaceuticals").

Figure 8 tells us that the development of ICTs leads to a decline in the number of agents still playing the game by the last hundred periods and a slight increase in mean residential time for surviving agents for middle-range ICT evolution, but here again, with further technological development the average agent's residential time goes down again. This suggests:

Hypothesis 4: As ICTs develop, the increased diffusibility of knowledge -both structured and unstructured-makes it ever harder for the average organization to achieve sustainability in the competitive advantage derivable from a given set of knowledge assets.

This is linked to Hypothesis 3 in that, in line with the paradox of value, the terms of the trade-off between residential time and profit maximization become ever less favorable to the organization and ever more beneficial to society as ICTs evolve. Product life cycles get shorter and windows of opportunity get smaller. The question then becomes: at what point will this discourage entry into an industry? A corollary of Hypothesis 4 above is the following:

Hypothesis 5: With the development of ICTs, the rents that surviving organizations receive from their knowledge assets, increases.

It might be seen here a possible manifestation of the winner-take-all phenomenon that characterizes the digital economy. With the stock market looking ever more like a lottery, the boom became vulnerable to Schumpeter's "gales of creative destruction" (Schumpeter, 1983). The problem with such phenomena is that, because outsiders are unable to evaluate an organization's knowledge base-and hence its prospects- they tend to result in bubbles.

A preference for the organic growth of an organization's knowledge assets appears to be a natural corollary of Hypothesis 2. The logic also applies to strategic alliances. What might then appear is a situation in which the higher costs of protecting intellectual property rights in an advanced ICT regime leads to a preference for organic growth and this shows up as a relative increase in the number of subsidiaries created relative to joint ventures or mergers. Differences in organization survival prospects following diffusion-blocking strategies are attenuated by ICT developments (Figure 7 and 10). ICTs may not change the logic of the process, but they do moderate the force with which the logic is applied. Therefore:

\section{Hypothesis 6: The development of ICTs favors organic growth rather than growth through mergers or joint ventures.}

The process of ICT development is a subtle one with two components: 1) a data processing component which facilitates the processes of codification and abstraction and hence speeds up the diffusion of informationcalled the diffusion effect; 2) a communicative component that reduces the need for codification and abstraction - labeled the bandwidth effect. The very early stages of ICT development-i.e., writing-were focused on the data processing component rather than the bandwidth component. For example the combined effects of printing technologies (diffusion) and the scientific revolution (codification and abstraction) contributed to a shrinking of the European cultural space between 1600 and 1900 and sped up industrialization (Eisenstein, 1979; Goody, 1986). Putting things down in writing - to establish a patent claim, to establish a contractual relationship, etc.- - extended the reach of transactions in both space and in time. They did this, however, by reducing the 
communication bandwidth. Later ICT developments-essentially built around telephony-increased the bandwidth and allowed a great deal of knowledge to flow more informally within and across organizations. Such knowledge was not necessarily of the same kind as flowed in the early phases. Finally, with the emergence of the Internet, email, videoconferencing, etc., progress is simultaneously confronted on the data processing and on the communicative front so that both diffusion effects and bandwidth effects are present simultaneously. Such an account is consistent with the plots of Figure 10. Therefore, the following can be suggested:

Hypothesis 7: Early stages of ICT development-such as writing-strongly favor the structuring of knowledge assets. Intermediate stages of ICT developments—such as the telephone-reduce the need for such structuring. But as these technologies further develop— such as through the Internet— the payoff to some further structuring rises once more.

Figure 7 showed a precipitous drop in the proportion of agents pursuing a diffusion-blocking strategy over time. Figure 10, however shows that this proportion, while still low, grows significantly as ICTs develop. Finally Figure 11 indicates that this proportionate increase is not accounted for by any significant increase in the actually number of agents pursuing a diffusion blocking strategy, but rather by a significant drop in the survival rate of those who fail to pursue such a strategy. This suggests the following hypothesis:

Hypothesis 8: Given the increased diffusibility of knowledge in advanced ICT regimes, higher levels of ICT development will increase the payoffs to stringent protection of intellectual property rights, and this, even in a Schumpeterian economy. Such strategies, bowever, will remain a minority preference.

Clearly, as ICTs develop, the diffusibility of knowledge is enhanced. While this has the effect of lowering the average level of rents that agents can earn from each knowledge asset, the knowledge assets are now available to a larger number of agents so that overall rental earnings actually go up. Yet competition intensifies. As Figure 11 indicates, the mean residential time of agents in the simulation goes down, but it does so at a faster rate for those not blocking diffusion than it does for those blocking diffusion. Thus the relative attractiveness of a diffusionblocking strategy goes up as ICTs develop. In effect, diffusion-blocking allows organizations to "make hay while the sun shines"-i.e., their life as monopoly rentiers may be briefer, but they can be more profitable.

What, if any, is the central message of these hypotheses taken as a whole? Are they worth testing empirically? Research on organizational evolution has been driven by two conflicting approaches (Levinthal, 1991). One perspective - the adaptationist—has focused on how individual organizations learn and adapt to their environment (Nelson \& Winter, 1982), while the other-the organizational ecology or organizational demography perspective- has emphasized the variation and selection of organizational forms as a way for a population of organizations to survive (Hannan \& Freeman, 1989). Although, to some extent, these two views are complementary (Amburgey \& Rao, 1996; Levinthal, 1991) they have adopted different attitudes towards knowledge. The broad perspective adopted by organizational ecologists and demographers of organizations is that, because of their structural inertia, organizations are seldom able to adapt to their environment (Carroll \& Hannan, 2000). Whatever learning or knowledge creation they achieve does not materially affect their survival prospects. Knowledge is viewed, much as genes are, as an unchanging organizational endowment that makes a more-or-less fixed contribution to its chances of surviving. The strategic management of knowledge by managers does not affect an organization's survival prospects. Nelson and Winter's (1982) approach to organizational evolution is quite different. In their work, evolutionary mechanisms are applied not to individual organizations in a population, but to those elements of their organizational knowledge that take the form of routines (Parmigiani \& Howard-Grenville, 2011). Knowledge management becomes, in effect, the management of routines.

Nelson and Winter, however, do not analyze the impact of such mechanisms on the evolution of the organizational population. It is very difficult to do so using traditional analytical methodologies since organizational populations, taken as groups of interacting economic actors, are instances of complex adaptive systems (Allen, Maguire \& McKelvey, 2011; Arthur, 2015; Arthur, Durlauf \& Lane, 1997; Carayannis \& Campbell, 2009; Page, 2011). We cannot suppose, therefore, that the effects of low-level knowledge-related processes will scale up in a linear fashion to more aggregated population levels. The sciences of complexity, however, have provided us with new methodological tools such as agent-based simulation modeling through 
which to approach the problem (Bookstaber, 2017; Epstein, 1999; Gatti, Fagiolo, Gallegati, Richiardi \& Russo, 2018; Gilbert, 2008; Miller \& Page, 2007; Railsback \& Grimm, 2011; Robertson, 2019; Watts \& Gilbert, 2014; Wilensky \& Rand, 2015). These kind of tools have been used before to successfully model knowledge dynamics problems (Boisot et al., 2003; Canals et al., 2004; Gilbert, Ahrweiler \& Pyka, 2014; Jang, Ju, Ryu \& Om, 2019; Kowalska-Styczeń, Malarz \& Paradowski, 2018). This complexity perspective has been used to deal with knowledge-related problems in several works found in the literature (Andriani, 2011; Boisot, 2011; Khvatova, Block, Zhukov \& Lesko, 2016; McElroy, 2000; Watts \& Gilbert, 2014).

In this paper agent-based simulation modeling has been used to link the strategic behavior of individual agents to emergent outcomes at the population level. What has been effectively seen is that the strategic choices exercised by an agent with respect to its knowledge assets have a significant impact both on the carrying capacity of its environment and on the mean residential time of the agent within it. Taking the agent to represent an organization and the parameter settings for knowledge structuring and diffusion blocking to represent the strategic choices of managers, it is clear that these findings are at odds with some of the basic tenets of the organizational ecology school, namely, that managerial choice cannot affect an organization's survival prospects. To strengthen this conclusion, the hypotheses advanced here would have to be investigated empirically.

It would also be worth investigating whether the knowledge intensity of the organization amplifies or limits the scope for managerial choice. Although a full-fledged knowledge-based theory of the organization is still not in place (Spender, 1996, 2002), there remains little doubt that the way organizations and institutions manage their knowledge has a tremendous impact on their competences and, as a consequence, on their performance (Sanchez, 2001). But does this vary with the organization's knowledge intensity? And, in turn, is the organization's knowledge intensity affected by ICT developments? It might be foreseen that future developments both of the conceptual framework and of our agent-based model will allow to address such issues.

\section{Conclusion}

Building on a conceptual framework, the I-Space, in this paper agent-based simulation modeling has been used to explore two issues:

1. The impact of strategic choice on the management of an organization's knowledge assets.

2. The impact of ICT evolution on the scope for strategic choice.

From the simulations, a number of empirically testable hypotheses have been extracted. Should these hypotheses get empirically corroborated, they would challenge a certain body of theorising - associated with organizational ecology and organizational demography - thus demonstrating the fruitfulness of the simulation approach to complex knowledge-based problems in the field of strategy. They would also bring out the relevance of the codification debate to the evolution of the knowledge economy by showing that, whatever the importance accorded to tacit knowledge by scholars, its differential possession gives rise to distinctive strategies.

\section{Acknowledgements}

The author wishes to express his most sincere gratitude tothe late Prof. Max Boisot and to Prof. Ian C. MacMillan, without whom this research would not have been possible.

\section{Declaration of Conflicting Interests}

The author declared no potential conflicts of interest with respect to the research, authorship, and/or publication of this article.

\section{Funding}

The author thanks the support from the Generalitat de Catalunya to the KIMO research group (2017-SGR1540) and from MINECO through the funding of the projects KESIR (CSO2009-09194) and KIBIS (CSO2012-33959). 


\section{References}

Abar, S., Theodoropoulos, G.K., Lemarinier, P., \& O’Hare, G.M.P. (2017). Agent Based Modelling and Simulation tools: A review of the state-of-art software. Computer Science Revien, 24, 13-33. https://doi.org/10.1016/j.cosrev.2017.03.001

Allen, P., Maguire, S., \& McKelvey, B. (2011). The sage handbook of complexity and management. Los Angeles: Sage.

Almeida, P., \& Kogut, B. (1999). Localization of Knowledge and the Mobility of Engineers in Regional Networks. Management Science, 45(7), 905-917. https://doi.org/10.1287/mnsc.45.7.905

Amburgey, T., \& Rao, H. (1996). Organizational ecology: Past, present and future directions. Academy of Management Journal, 39(5), 1265-1286. https://doi.org/10.5465/256999

Ancori, B., Bureth, A., \& Cohendet, P. (2000). The Economics of Knowledge: The Debate about Codification and Tacit Knowledge. Industrial and Corporate Change, 9(2), 255-287. https://doi.org/10.1093/icc/9.2.255

Andreu, R., Baiget, J., \& Canals, A. (2008). Firm-specific knowledge and competitive advantage: Evidence and KM practices. Knowledge and Process Management, 15(2), 97-106. https://doi.org/10.1002/kpm.302

Andriani, P. (2011). Complexity and innovation. In The SAGE handbook of complexity and management (pp. 454-470). Los Angeles: Sage.

Appleyard, M.M. (1996). How Does Knowledge Flow? Interfirm Patterns in the Semiconductor Industry. Strategic Management Journal, 17(Special Issue: Knowledge and the Firm), 137-154.

https://doi.org/10.1002/smj.4250171112

Arthur, W. B. (2015). Complexity and the economy. Oxford University Press.

Arthur, W.B., Durlauf, S.N., \& Lane, D.A. (1997). The Economy as an Evolving Complex System II. Reading, MA: Perseus Books.

Asheim, B.T., Boschma, R., \& Cooke, P. (2011). Constructing Regional Advantage: Platform Policies Based on Related Variety and Differentiated Knowledge Bases. Regional Studies, 45(7), 893-904.

https://doi.org/10.1080/00343404.2010.543126

Audretsch, D.B. (2000). Knowledge, Globalization, and Regions: An Economist's Perspective. In J. H. Dunning (Ed.), Knowledge, Globalization, and the Knowledge-Based Economy (pp. 63-81). Oxford University Press.

https://doi.org/10.1093/0199250014.003.0004

Barabási, A.-L. (2002). Linked: The new science of networks. Cambridge, MA: Perseus Pub.

Barron, D.N. (2001). Simulating the Dynamics of Organizational Populations: A Comparison of Three Models of Organizational Entry, Exit, and Growth. In A. Lomi \& E. R. Larsen (Eds.), Dynamics of Organizations: Computational Modeling and Organization Theories (pp. 209-242). Menlo Park, CA: AAAI Press / The MIT Press.

Bell, D. (1999). The coming of post-industrial society. New York: Basic Books.

Boisot, M.H. (1995a). Information space: A framework for learning in organizations, institutions and culture. London: Routledge.

Boisot, M.H. (1995b). Is your firm a creative destroyer? Competitive learning and knowledge flows in the technologies of firms. Research Policy, 24(4), 489-506. https://doi.org/10.1016/S0048-7333(94)00779-9

Boisot, M.H. (1996). Institutionalizing the Labour Theory of Value: Some Obstacles to the Reform of Stateowned Enterprises in China and Vietnam. Organization Studies, 17(6), 909-928.

https://doi.org/10.1177/017084069601700602

Boisot, M.H. (1998). Knowledge assets: Securing competitive advantage in the information economy. Oxford University Press.

Boisot, M.H. (2011). Knowledge management and complexity. In The SAGE handbook of complexity and management (pp. 436-453). Los Angeles: Sage. 
Boisot, M.H., \& Canals, A. (2004). Data, information and knowledge: Have we got it right?. Journal of Evolutionary Economics, 14, 43-67. https://doi.org/10.1007/s00191-003-0181-9

Boisot, M.H., Canals, A., \& MacMillan, I. (2003). Neoclassical versus Schumpeterian approaches to learning: A knowledge-based simulation approach. In J.-P. Müller \& M.-M. Seidel (Eds.), ABS 2003: 4th Workshop on Agent-Based Simulation (pp. 98-103). Erlangen: Society for Modeling and Simulation International, SCSEuropean Publishing House.

Boisot, M.H., \& Li, Y. (2005). Codification, Abstraction, and Firm Differences: A Cognitive, Information-based Perspective. Journal of Bioeconomics, 7, 309-334. https://doi.org/10.1007/s10818-005-3940-x

Boisot, M.H., MacMillan, I., \& Han, K.S. (2007). Property Rights and Information Flows: A Simulation Approach. Journal of Evolutionary Economics, 17(1), 63-93. https://doi.org/10.1007/s00191-006-0031-7

Boisot, M.H., \& Nordberg, M. (2011). A Conceptual Framework: The I-Space. In M. H. Boisot, M. Nordberg, S. Yami, \& B. Nicquevert (Eds.), Collisions and collaboration: The organization of learning in the ATLAS experiment at the LHC (pp. 28-54). Oxford University Press. https://doi.org/10.1093/acprof:oso/9780199567928.003.0003

Bookstaber, R. (2017). The End of Theory: Financial Crises, the Failure of Economics, and the Sweep of Human Interaction. Princeton, NJ: Princeton University Press. https://doi.org/10.1515/9781400884964

Canals, A., Boisot, M.H., \& MacMillan, I. (2004). Simulating I-Space (SimISpace): An agent-based approach to modeling knowledge flows (Working Paper No. WP04-006; IN3:UOC Working Paper Series). UOC. https://doi.org/10.7238/in3wps.v0i5.877

Canals, A., Boisot, M.H., \& MacMillan, I.C. (2008). The spatial dimension of knowledge flows: A simulation approach. Cambridge Journal of Regions, Economy and Society, 1(2), 175-204. https://doi.org/10.1093/cjres/rsm007

Carayannis, E.G., \& Campbell, D.F.J. (2009). “Mode 3'and'Quadruple Helix”: Toward a 21st century fractal innovation ecosystem. International Journal of Technology Management, 46(3-4), 201-234.

https://doi.org/10.1504/IJTM.2009.023374

Carley, K.M. (1999). On generating hypotheses using computer simulations. Systems Engineering, 2(2), 69-77. https://doi.org/10.1002/(SICI)1520-6858(1999)2:2<69::AID-SYS3>3.0.CO;2-0

Carroll, G.R., \& Hannan, M.T. (2000). The Demograpby of Corporations and Industries. Princeton, NJ: Princeton University Press. https://doi.org/10.1515/9780691186795

Castells, M. (1996). The rise of the network society. In The information age: Economy, society and culture. Oxford: Blackwell.

Castells, M. (2001). La Galaxia Internet. Barcelona: Plaza \& Janés. https://doi.org/10.1007/978-3-322-89613-1

Child, J. (1972). Organizational structure, environment, and performance: The role of strategic choice. Sociology, 6, 1-22. https://doi.org/10.1177/003803857200600101

Ciborra, C.U., \& Andreu, R. (2002). Knowledge across Boundaries: Managing Knowledge in Distributed Organizations. In C.W. Choo \& N. Bontis (Eds.), The strategic management of intellectual capital and organizational knowledge (pp. 575-604). Oxford University Press.

Cohendet, P., Parmentier, G., \& Simon, L. (2017). Managing knowledge, creativity and innovation. In H. Bathelt, P. Cohendet, S. Henn, \& L. Simon (Eds.), The Elgar Companion to Innovation and Knowledge Creation (pp. 197-214). Cheltenham: Edward Elgar. https://doi.org/10.4337/9781782548522.00021

Davenport, T.H., \& Prusak, L. (1998). Working knowledge: How organizations manage what they know. Boston, MA: Harvard Business School Press.

Davis, J.P., Eisenhardt, K., \& Bingham, C.B. (2007). Developing Theory Through Simulation Methods. Academy of Management Review, 32(2), 480-499. https://doi.org/10.5465/amr.2007.24351453 
DiMaggio, P. (2001). Conclusion: The Futures of Business Organization and Paradoxes of Change. In P. DiMaggio (Ed.), The twenty-first-century firm: Changing economic organization in international perspective (pp. 210-243). Princeton University Press. https://doi.org/10.1515/9781400828302

Dunning, J.H. (2000). Regions, Globalization, and the Knowledge Economy: The Issues Stated. In J.H. Dunning (Ed.), Regions, Globalization, and the Knowledge Economy (pp. 7-41). Oxford University Press. https://doi.org/10.1093/0199250014.003.0002

Eisenstein, E.L. (1979). The Printing Press as an Agent of Change: Communications and Cultural Transformations in Early Modern Europe. Cambridge: Cambridge University Press.

Epstein, J.M. (1999). Agent-Based Computational Models And Generative Social Science. Complexity, 4(5), 41-60. https://doi.org/10.1002/(SICI)1099-0526(199905/06)4:5<41::AID-CPLX9>3.0.CO;2-F

Evans, P., \& Wurster, T.S. (2000). Blown to Bits: How the New Economics of Information Transforms Strategy. Boston: Harvard Business School Press.

Gatti, D.D., Fagiolo, G., Gallegati, M., Richiardi, M., \& Russo, A. (Eds.). (2018). Agent-based models in economics: A toolkit. Cambridge: Cambridge University Press.

Gilbert, N. (2008). Agent-based models (Issue 153). Thousand Oaks, CA: Sage. https://doi.org/10.4135/9781412983259

Gilbert, N., Ahrweiler, P., \& Pyka, A. (2014). Simulating knowledge dynamics in innovation networks. Berlin: Springer. https://doi.org/10.1007/978-3-662-43508-3

Goody, J. (1986). The Logic of Writing and the Organization of Society. Cambridge: Cambridge University Press. https://doi.org/10.1017/CBO9780511621598

Hahn, U., Chater, N., Lamberts, K., \& Shanks, D. (1997). Concepts and similarity. In Knowledge, Concepts, and Categories (pp. 43-92). Cambridge, MA: MIT Press.

Hall, E.T. (1976). Beyond culture. New York: Doubleday.

Hannan, M.T., \& Freeman, J. (1989). Organizational Ecology. Cambridge, MA: Harvard University Press.

Hislop, D., Bosua, R., \& Helms, R. (2018). Knowledge management in organizations: A critical introduction. Oxford: Oxford university press.

Holland, J.H. (1992). Adaptation in Natural and Artificial Systems. Cambridge, MA: MIT Press. https://doi.org/10.7551/mitpress/1090.001.0001

Jang, J., Ju, X., Ryu, U., \& Om, H. (2019). Coevolutionary Characteristics of Knowledge Diffusion and Knowledge Network Structures: A GA-ABM Model. Journal of Artificial Societies and Social Simulation, 22(3), 3. https://doi.org/10.18564/jasss.4037

Khvatova, T., Block, M., Zhukov, D., \& Lesko, S. (2016). How to measure trust: The percolation model applied to intra-organisational knowledge sharing networks. Journal of Knowledge Management, 20(5), 918-935. https://doi.org/10.1108/JKM-11-2015-0464

Klarl, T. (2014). Knowledge diffusion and knowledge transfer revisited: Two sides of the medal. Journal of Evolutionary Economics, 24(4), 737-760. https://doi.org/10.1007/s00191-013-0319-3

Kowalska-Styczeń, A., Malarz, K., \& Paradowski, K. (2018). Model of Knowledge Transfer Within an Organisation. Journal of Artificial Societies and Social Simulation, 21(2), 3. https://doi.org/10.18564/jasss.3659

Leonard, D. (1995). Wellsprings of knowledge: Building and sustaining the sources of innovation. Boston, MA: HBS Press.

Leonard, D., \& Barton, M. (2014). Knowledge and the management of creativity and innovation. In The Oxford handbook of innovation management (pp. 121-138). Oxford University Press. https://doi.org/10.1093/oxfordhb/9780199694945.013.005

Lessig, L. (2002). The future or ideas: The fate of the commons in a connected world. New York: First Vintage Books. 
Levinthal, D.A. (1991). Organizational Adaptation and Environmental Selection-Interrelated Processes of Change. Organization Science, 2(1), 140-145. https://doi.org/10.1287/orsc.2.1.140

Levinthal, D.A. (1997). Adaptation on Rugged Landscapes. Management Science, 43(7), 934-950. https://doi.org/10.1287/mnsc.43.7.934

Machlup, F. (1983). Knowledge: Its creation, distribution, and economic significance. Princenton, NJ: Princeton University Press. https://doi.org/10.1515/9781400856015

Massingham, P. (2020). Knowledge management: Theory in practice. London: SAGE Publications Limited.

Mayr, E. (1982). The growth of biological thought: Diversity, evolution, and inheritance. Cambridge, MA: The Belknap Press of Harvard University Press.

McCraw, T.K. (2009). Prophet of innovation. Cambridge, MA: Harvard University Press. https://doi.org/10.4159/9780674040779

McElroy, M.W. (2000). Integrating complexity theory, knowledge management and organizational learning. Journal of Knowledge Management, 4(3), 195-203. https://doi.org/10.1108/13673270010377652

Miller, J.H., \& Page, S.E. (2007). Complex adaptive systems: An introduction to computational models of social life. In Princeton studies in complexity. Princeton, NJ: Princeton University Press.

Minar, N., Burkhart, R., Langton, C., \& Askenazi, M. (1996). The SWARM Simulation System: A Toolkit for Building Multi-Agent Simulations. Technical report, Swarm Development Group. Santa Fe, NM: Santa Fe Institute.

Mitchell, M. (1996). An introduction to genetic algorithms. Cambridge, MA: The MIT Press.

Nee, V., \& Swedberg, R. (2005). Introduction. In V. Nee \& R. Swedberg (Eds.), The economic sociology of capitalism. Princeton, NJ: Princeton University Press. https://doi.org/10.1515/9780691217932-003

Nelson, R.R., \& Winter, S.G. (1982). An Evolutionary Theory of Economic Change. Cambridge, MA: Belknap Press of Harvard University Press.

Oluikpe, P. (2012). Developing a corporate knowledge management strategy. Journal of Knowledge Management, 16(6), 862-878. https://doi.org/10.1108/13673271211276164

Page, S.E. (2011). Diversity and complexity. In Primers in complex systems. Princenton, NJ: Princeton University Press.

Parmigiani, A., \& Howard-Grenville, J. (2011). Routines Revisited: Exploring the Capabilities and Practice Perspectives. Academy of Management Annals, 5(1), 413-453. https://doi.org/10.5465/19416520.2011.589143

Railsback, S.F., \& Grimm, V. (2011). Agent-based and individual-based modeling: A practical introduction. Princenton, NJ: Princeton university press.

Robertson, D.A. (2019). Agent-based strategizing. Cambridge, MA: Cambridge University Press. https://doi.org/10.1017/9781108767835

Sanchez, R. (2001). Knowledge management and organizational competence. Oxford: Oxford University Press.

Saviotti, P.P. (1998). On the dynamics of appropriability, of tacit and of codified knowledge. Research Policy, 26, 843-856. https://doi.org/10.1016/S0048-7333(97)00066-8

Saviotti, P.P. (2011). Knowledge, complexity and networks. In C. Antonelli (Ed.), Handbook on the economic complexity of technological change. Edward Elgar, Cheltenham (pp. 141-180). Cheltenham: Edward Elgar.

Schumpeter, J.A. (1983). The Theory of Economic Development: An Enquiry into Profits, Capital, Credit, Interest and the Business Cycle. New Brunswick, NJ:: Transaction Publishers.

Spender, J.C. (1996). Making knowledge the basis of a dynamic theory of the firm. Strategic Management Journal, 17(Winter Special Issue), 45-62. https://doi.org/10.1002/smj.4250171106 
Spender, J.C. (2002). Knowledge Management, Uncertainty, and an Emergent Theory of the Firm. In C. W.

Choo \& N. Bontis (Eds.), The strategic management of intellectual capital and organizational knowledge (pp. 149-162).

New York: Oxford University Press.

Stein, J., Ridderstrale, J., \& Sanchez, R. (2001). Managing the dissemination of competences. In Knowledge management and organizational competence (pp. 63-76). Oxford: Oxford University Press.

https://doi.org/10.1093/acprof:oso/9780199259281.003.0003

Storper, M. (2000). Globalization and Knowledge Flows: An Industrial Geographer's Perspective. In J.H. Dunning (Ed.), Regions, Globalization, and the Knowledge Economy (pp. 42-62). Oxford University Press. https://doi.org/10.1093/0199250014.003.0003

Teece, D.J. (2000). Managing Intellectual Capital. Oxford: Oxford University Press.

Watts, C., \& Gilbert, N. (2014). Simulating innovation: Computer-based tools for retbinking innovation. Cheltenham: Edward Elgar Publishing. https://doi.org/10.4337/9781783472536

Wilensky, U., \& Rand, W. (2015). An introduction to agent-based modeling: Modeling natural, social, and engineered complex systems with NetLogo. Boston, MA: MIT Press.

Winter, S.G., Szulanski, G., Choo, C.W., \& Bontis, N. (2002). Replication of Organizational Routines: Conceptualizing the Exploitation of Knowledge Assets. In The Strategic Management of Intellectual Capital and Organizational Knowledge (pp. 207-221). New York: Oxford University Press.

\section{(c) (i) $\$$}

Article's contents are provided on an Attribution-Non Commercial 4.0 Creative commons International License. Readers are allowed to copy, distribute and communicate article's contents, provided the author's and Intangible Capital's names are included. It must not be used for commercial purposes. To see the complete license contents, please visit https://creativecommons.org/licenses/by-nc/4.0/. 